\title{
Study of Influencing Factors of Apple Juice Export of Xinjiang Area
}

\author{
Zhang Qiongyue, Zhang Chuanhui \\ College of Economic and Management, Tarim University, Alar, Xinjiang, 843300
}

Key words: apple juice; export, influencing factors

\begin{abstract}
As the largest apple juice producing country, China makes full use of its own advantages to stabilize the its predominance in apple juice. At the same time, improving the profits of apple juice producer is very important. The exportation of concentrated apple juice reflects the industrialization development of forestry and fruit industry in Xinjiang area. Therefore the discussion for the influencing factors of the apple juice export in Xinjiang area is extremely essential, which not only has a very important actual meaning for the forestry and fruit industry development in Xinjiang, but also has a very important research significance for promoting the economic growth in Xinjiang.

Introduction

The status of largest apple producing country provides exceptional advantages for the export of concentrated apple juice of China. The geographical advantage of Xinjiang offers extremely favorable planting condition for producing apple. In recent years, though the output of concentrated apple juice in Xinjiang has been increasing year by year and the export increases substantially, the apple juice export of Xinjiang still has many problems when compared with other developed regions of our country. For example, there are many problems in product structure, product effectiveness and export mechanism of apple juice export. Especially the growth pattern of apple juice industrial product export in Xinjiang is still extensive. Therefore, at present it is essential to find the problems of apple juice export of Xinjiang, analyze the factors affecting it, promote the export and stimulate the rapid economic development in Xinjiang.
\end{abstract}

\section{Analysis of the problems of Xinjiang apple juice export}

Apple juice is the second popular juice in the world and its selling market is distributed in the developed countries such as America, England, Germany, Netherlands, Israel and Australia. The demand of international market keeps growing steadily. With the rapid growth of the production and sales volume of the pure juice and juice beverages in world beverage market, the market demand of the concentrated apple juice has a steady rise because it's the basic ingredient of apple juice beverage. Though the demand is increasingly high, the delayed construction of professional raw material fruit base restricts the apple juice export of Xinjiang largely. This is due to the lagging of the professional raw material fruit base. Many manufacturing enterprises still use the defective fruit in the fresh fruit and dropping fruit as the processing raw material, which is easy to cause the following negative influences. For example, the insufficient supply of the raw material fruit will cause the processing enterprises to have a open plunder for the raw material, affecting the industry order; Raw material fruit are not the high-acid variety and it will influence the level and price of the juice. Another example, The high proportion of the dropping and defective fruit will cause excessive patulin content in the juice. However, European Union is strict with the patulin and it is prone to cause trade barier. What's more, China apples are mainly late maturing varieties and the period of picking and selling is from August to October. This will cause insufficient time to process the raw material fruit and the processing enterprises will have much pressure to process the raw material. The raw material has to be stored for a long time and in the storage process, some apples are prone to go bad. Thus the juice quality is hard to be guaranteed. At last, the problem of low level product structures exists in the apple juice export of Xinjiang for a long time. The reason is that the 
technical content of the apple juice product in Xinjiang is low and the additional value is low, the old-fashioned variety can not follow the quick market changes and competitiveness in international market is weak.

At present, the concentrated apple juice producing and trading enterprises in Xinjiang are many and there are also advanced technology leading enterprises, which have advanced producing equipments of world class, strong equipment improving ability and technological assimilation ability. However, with the increasing of the export volume of juice and price, the enterpriser develops and get stronger and the industry influence is improving. But adaptability to changes in the market of the enterprises is weak. The process of new product development, deep processing, merger and reorganization of assets and cultivation of new growth points is slow. The adaptability to changes in the market of the operating mechanism and management systems is weak, such as competitive mechanism. The market economy is competitive economy, which is realized by competitive mechanism. This is the reality that many apple juice enterprises can not avoid. The introduce of the competitive mechanism will enable the enterprises to become independent in the market and make the advanced enterprise to develop and expand in the market. In contrast, the backward development can not turn around enterprises which are in the falling situation, and these enterprises will be sifted out and withdraw from the market. In addition, in the renovation mechanism, If the apple juice enterprises want to develop continuously and increase the profits, they should pay attention to the demands of international apple juice market and constantly advance the technology and renovation. However, Xinjiang apple juice export enterprises have no impetus and pressure of technical renovation and have no essential financial resources and power to carry out the technical renovation. So the technology lags behind and the benefits are low. At last, in the aspect of enterprise operating mechanism, many apple juice producing enterprises in Xinjiang is not flexible in operation, lacks effective market information channels and effective selling network of international apple juice market, have a slow response to the changes of supply-demand relationship in international market. The world-class international apple juice brand is not established and the foreign trade talents who are familiar with the WTO principle is scanty.

In recent years, export volume of Xinjiang apple juice has been increasing, but its economic benefit is extremely low. From 2010, the price of Xinjiang concentrated apple juice has being increasing on the whole and the trend of industry recovery is obvious. However, for a long time, Xinjiang apple juice enterprises lack the ability of accumulation and self-development, their structures are unreasonable and the management is relatively extensive. The economic benefit is good only when the it is promoted by the foreign and domestic economy. Their ability of relizing the benefits depending on themselves is weak. The additional value of apple juice product in Xinjiang is low and the exporting price is low. Though there is a certain exporting volume, the actual profit is few. At the same time, The apple juice enterprise in Xinjiang aims to realize its benefits with its quantity of export, and their object is to export more. They will be happy if they can get into international market, no matter whether they will get benefit or not. This kind of extensive growth pattern will grow when the international market is in a good condition, it also can grow when the international market is not in good condition. Its results is paying the heavy price of losing benefits. What's more, China exporting channel of apple juice product is controlled by foreign merchants and they force down the product price to a very low level. This is root reason why the economic benefit of apple juice exporting enterprises are low at present. Generally, the selling profits of apple juice enterprise are low and the product exporting of most of the enterprises are in a maintenance operation and they lack support from profits. The high consumption of the energy increases the exporting cost. With the rapid development of the concentrated juice industry, the overall productivity scale expands rapidly, which causes the relative shortage of the apple resource of upstream raw material, strengthening scrambling of raw material and increasing of the raw material price. The purchasing cost of the raw material accounts more than sixty percent in the producing cost. So the increasing of raw material price brings severe stress for company the company to control the manufacture cost. Furthermore, the pressure of coal, electricity and oil transportation in Xinjiang restricts the production, operation and foreign trade export of Xinjiang 
apple juice.

\section{The analysis of the factors influencing the Xinjiang apple juice export}

To a large extent, the foreign and domestic economic situation decides whether Xinjiang apple juice export has good prospect and enormous potential. With the strengthening and improvement of the macro-control, the implementation of the moderate fiscal and currency policy, the controlling of the excessively rapid growth of the fixed asset investment scale, enhancing of the urban and rural household consumption and the strengthening of the pulling effect of consumption for the economic growth, Economy in China keeps rapid development. However, it needs to be noticed that if focus of economic work is put in transforming the economic growth pattern, different influences will be brought to domestic industry development inevitably and some uncertain factors will definitely become the main factors which restrict the rapid growth of Xinjiang apple juice product. Meanwhile, the increasing demands for healthy and nutrient beverages in foreign countries and the enormous consumption market in developing countries will stimulate the growth of the concentrated apple juice consumption amount tremendously. Judging from the international economic situation, the export of apple juice product will keep its rapid growth owing to the rapid development of the international economy. The adjustment of the international industrial structure creates advantages for the opening to the outside world and international adapting degree of China apple juice industry. At present, the world economy is bottoming out and has the trend of increasing, the international trade is improving, the speed of adjusting and shifting the world industry structure is increasing and the transnational investment is picking up. This kind of situation provides advantages for China apple juice industry to make better use of the foreign and domestic markets, two kind of resources and accelerates development.

The enhancing of the technical content and quality of exporting product of China apple juice industry and the adding of additional value of exporting product is the prospect of product exporting of China apple juice industry in the future. The export of Xinjiang apple juice will face the competition from Argentina, Chile, Polan and other countries in the international market. The apple of other countries such as Argentina has more acidity than apple in China, so in the past many Xinjiang enterprises competed with their cost advantages. But the demand of international market becomes higher and the strategy of price war can not meet the market requirements obviously. For the present production status of apple juice in Xinjiang, the quality of Xinjiang apple juice product has some differences compared to that of the developed countries. It has the problems of low level, low technical content, low processing depth, low product quality and other problems. From the perspective of reality, the problem of quality still decides the success and space of the export of China apple juice product. Moreover, the international apple juice is developing toward the directions of green ecology and security, which makes new and higher requests for the apple juice product export from various aspects such as quality, variety, level and safety and brings new challenge.

The inherent advantages of the Xinjiang apple juice industry product in international market competition is its cost and price, which may keep for a certain period in the future competition, but the time will not be too long. Concentrated apple juice industry belongs to resource and labor intensive processing industry and it always has resource and cost advantages. Apple juice product is not only belongs to labor intensive industry, but also belongs to resource intensive industry. In Xinjiang, the resource is sufficient and the price is low. The percentage of wages in product cost is low, which ranks 52th in various countries of the world; Xinjiang has rich apple resource with good quality and low price and it can support the apple juice product to participate in the international market competition. But undoubtedly the product competition is competition of quality and price. The RMB exchange rate is floating upward and the freight rate is increasing because of the increasing of oil price. These are the reasons which causes the rise of exporting price of concentrated apple juice of our country. After enter into the new-squeezing season, the price of the apple raw material will keep rise. Though the insufficient raw material supply causes the sharp rise of the price in recent two years, the comparative advantage will reduce. For another, for the 
concentrated apple juice industry which is encumbered with excessive competition and excessively rapid growth of annual production capacity, the rising of the raw material price will promotes it to integrate the industry and promotes the benign development of the industry. Through European countries still makes every endeavor to improve the automaticity of the productivity, increase the market share by lowering the cost, our country still has enormous potential in reducing the cost. The comparative advantage of energy, resouce, environment and labor of our country will not exist. The natural resouce will become scare thing and correspondingly their usage price will gradually increase. From this we can see that the cost and price advantages of apple juice enterprise of our countries will not keep too long in the future competition.

Xinjiang apple juice product export has great potential in the developing of sales network and brand. The establishment of international sales network is very important. In terms of the apple juice export of our country, the growth of marketing ability in international apple juice market is far less than growth of marketability. Many apple juice products, especially the product with high additional value still depends on the foreign sale channels. The establishment of the sales network in foreign apple juice market is a long-term work which needs much initial investment, including talents training, advertising, the establishment of marketing points and sales network. But if we want exploit the international market, we shall establish and perfect the sales network in international market. The competition in international apple juice market has entered into the competition of brand. Famous brand is the permit for the transnational company to get into the apple juice markets of various countries. Xinjiang apple juice product still hasn't establish a famous brand in the international market, which is a distinctive sign showing the competitiveness deficiency of product in China apple juice industry. At the same time, many Xinjiang apple juice producing enterprises lower the level of their products because the packaging is low and lacks ornament. Therefore, for expanding the export, we shall make efforts in the package specification. Besides, we shall break the trade barrier, establish the industry injury alert mechanism, make full use of the WTO dispute settlement mechanism and protect the rights and interests of apple juice enterprises of our country.

\section{Reference:}

[1] Dou Changxiao, Huoxuexi. The Study of Influencing Factors of China Apple Juice Export [J], Northern Horticulture, 2013 (18).

[2] Han Yongqi. Five Factors and Problems is Affecting the Apple Juice Export of China [J]. Feed industry, 2011(04).

[3] Dou Changxiao. The Study of Export Trade of China Apple Juice [D]. Northwest Agriculture Forestry University, 2014.

[4] Du Kun. The Study of the Influencing Factors of China Apple Export [D]. Chinese Academy of Agricultural Sciences , 2012. 